\title{
Factors that Could Increase Mortality in Patients with H1N1
}

\author{
Ayşe Şahin Tutak ${ }^{1 *}$, Ramazan Celik², Hakan Sezgin Sayıner ${ }^{3}$ and Atilla Tutak ${ }^{4}$ \\ ${ }^{1}$ Department İnternal Medicine, Adıyaman University of Medical Faculty, Adıyaman, Turkey \\ ${ }^{2}$ Department Chest Disease and Tuberculosis, Adıyaman University of Medical Faculty, Adiyaman, Turkey \\ ${ }^{3}$ Department İnfections Disease and Microbiology, Adiyaman University of Medical Faculty, Adiyaman, Turkey \\ ${ }^{4}$ Department Anestesia and Reanimation, Adiyaman University of Medical Faculty, Adıyaman, Turkey
}

"Corresponding Authors: Ayşe Şahin Tutak, Department of İnternal Medicine, Adıyaman University of Medical Faculty, Adıyaman, Turkey, Tel: + 904162161015; Fax: +904162161015; E-Mail: aysesahintutak@ hotmail.com

Received: 05 December 2017; Accepted: 15 January 2018; Published: 19 January 2018

\begin{abstract}
Objective: In this study, clinical and vital parameters of 5 patients who were being followed up at intensive care unit due to $\mathrm{H} 1 \mathrm{~N} 1$ were retrospectively analyzed and the clinical findings that should not be overlooked were stressed.
\end{abstract}

Method: Clinical follow ups of 5 patients whose H1N1 diagnoses were verified with PCR technique were recorded by the attending physician and vital parameters were recorded from patient files and an overall assessment was done.

Results: Oxygen saturation of 4 out of 5 patients whose mean age was 48 years (range 43-59) was $\leq 85 \%$ on admission and all of four died. Symptoms had begun 4-5 days before admission in 3 of these dying patients, exact data could not be obtained in another patient due to mental retardation. Oxygen saturation of the only surviving patient was $91 \%$ on admission and symptoms had begun one day ago. All patients had an accompanying disease and one had pregnancy. A significant improvement was observed on chest X-rays of 2 out of 4 dying patients, a significant radiological improvement was not detected in the forth case as the patient died within 36 hours, whether an improvement was obtained was not evaluated with X-ray in the third patient as she was pregnant. Gastric 
drainage was present in the first 3 dying patients. The forth case could not be completely evaluated as he/she died early.

Conclusion: The day of treatment commencement and presence of an accompanying disease were found as important factors for influenza-related mortality and we suggest that central nervous system (CNS) should be evaluated in patients whose clinical condition does not improve despite radiological improvement. In addition, blood drug level should be examined to see whether absorption is sufficient in case of high amounts of gastric drainage for providing an effective treatment.

Keywords: Influenza; Mortality; Clinical follow up

\section{Introduction}

2009 pandemic influenza A (H1N1) virus which carries the genes of human, swine and avian influenza first emerged in Maxico in April 2009 and rapidly spread to many other countries [1,2]. Clinical manifestation of influenza may vary between a mild upper respiratory tract infection and a life-threatening severe disease. Mild and uncomplicated seasonal influenza is characterized by fever, cough, sore throat, rhinore, headache, myalgia, fatigue and shivering. Dyspnea, tacchypnea, hypoxia and/or pulmonary radiological findings, encephalopathy, encephalitis, severe dehydration, renal failure, multi-organ failure, myocarditis, rhabdomyolysis, invasive secondary bacterial infection or septic shock may be seen in severe and complicated influenza [3,4]. Severe disease also includes exacerbation of a coexisting chronic disease and any other diseases which require hospitalization [3]. Patients who are suspected to have severe or complicated influenza should be hospitalized in intensive care unit. These patients should be treated with anti-viral therapy, antibiotics for secondary infections, non-invasive or invasive mechanical ventilation support and general supportive therapies. Patients should be treated with early and correct treatment options suggesting that mortality rates may be high in subjects who have a co-existing chronic disease, particularly in presence of a pandemic.

In this study, patient follow up files and clinical follow ups of 5 patients who were admitted to intensive care unit with pre-diagnosis of H1N1 and whose diagnoses were verified with laboratory tests were evaluated as a whole.

\section{Method}

In this retrospective study, clinical and laboratory follow ups and patient files of the patients who were hospitalized in intensive care unit of our hospital due to pre-diagnosis of H1N1 between 04.01.2016 and 25.01.2016 and whose diagnoses were verified by Reference Laboratory of Public Health Institution were evaluated as a whole .

\section{Results}

Clinical follow ups of five patients were recorded by the attending physician and vital-laboratory parameters were recorded from archive files. Mean age of the patients was 48 years (range 43-59) and all had an accompanying disease or a risk factor. Symptoms had begun 4-5 days before admission in 3 of these dying patients, exact data could not be obtained in another patient due to mental retardation and living alone. Four patients died, three within the first 4 days and another on day 9 . Oxygen saturations on admission were 63\%, 85\%, 45-46\%. Short term CPAP 
was tried in 4 cases and elective intubation was applied by sedation with midazolam-propofol thereafter as respiratory rate increased and hypoxia continued. All 5 patients were started oseltamivir $75 \mathrm{mg}$ bid and empirical antibiotic therapy when they were admitted to intensive care unit. High fever was present in $2^{\text {th }}$ and $4^{\text {th }}$ cases. The patient who survived never had high fever and remaining 4 patients who died had high fever before dying. Single free drainage from naso-gastric (NG) tube was $200 \mathrm{cc}$ or above in 3 patients. The forth patient could not be evaluated for drainage from naso-gastric tube as he/she was lost within 36 hours. The fifth patient did not have drainage from NG tube (Table 1). All dying patients had fever, tachycardia, tachypnea, 2 cases had hypotension, hypoxia continued in 3 cases (Table 2). Chest X-ray findings had improved in 2 of dying patients (Figure 1 and 2), an improvement was not detected in another case who died within 36 hours, control radiography was not obtained during the last 4 days in the pregnant patient.

\begin{tabular}{|c|c|c|c|c|c|}
\hline & Case -1 & Case -2 & Case $\mathbf{- 3}$ & Case -4 & Case -5 \\
\hline Age & 47 & 46 & 43 & 45 & 59 \\
\hline Gender & $\mathrm{K}$ & $\mathrm{K}$ & $\mathrm{K}$ & $E$ & $E$ \\
\hline Coexisting disease & $\begin{array}{l}\text { DM, peripheral } \\
\text { vascular disease }\end{array}$ & $\begin{array}{l}\text { Diabetes, } \\
\text { asthma }\end{array}$ & Pregnancy & $\begin{array}{l}\text { Obesity, ARF, } \\
\text { MR }\end{array}$ & $\begin{array}{l}\text { Postop CABG } \\
\text { day } 7\end{array}$ \\
\hline $\begin{array}{l}\text { Duration between } \\
\text { symptom onset } \\
\text { and ICU } \\
\text { admission } \\
\text { (treatment) }\end{array}$ & 4 days & 5 days & 5 days & Not known & $\begin{array}{l}\text { Within } 24 \\
\text { hours }\end{array}$ \\
\hline $\begin{array}{l}\text { Duration of } \\
\text { hospital stay }\end{array}$ & 4 & 9 & 4 & 2 & 10 \\
\hline EX & EX & EX & EX & EX & Discharge \\
\hline sO2 on admission & 45 & 48 & 85 & 63 & 91 \\
\hline ABG-Ph & 7,29 & 7,3 & 7,49 & 7,18 & 7,5 \\
\hline $\mathrm{pCO2}$ & 46,1 & 43 & 25 & 63 & 28,5 \\
\hline pO2 & 15,3 & 25 & 46 & 40 & 59,1 \\
\hline $\begin{array}{l}\text { Fever on } \\
\operatorname{admission}\left(C^{\circ}\right)\end{array}$ & 36.3 & 37,6 & 36,8 & 37,9 & 36,9 \\
\hline $\begin{array}{l}\text { Blood pressure on } \\
\text { admission }\end{array}$ & $167 / 78$ & $130 / 60$ & $141 / 72$ & $115 / 58$ & $155 / 80$ \\
\hline $\begin{array}{l}\text { Respiratory rate } \\
\text { on admission }\end{array}$ & $45-55$ & 57 & 35 & 32 & 28 \\
\hline $\begin{array}{l}\text { Pulse rate on } \\
\text { admission }\end{array}$ & 130 & 110 & 136 & 112 & 85 \\
\hline $\begin{array}{l}\text { Ventilation } \\
\text { support }\end{array}$ & MV & MV & MV & MV & MV-CPAP \\
\hline Sedation & Preop+dormi & Dormicum & Norodol & Dormicum & Dormicum \\
\hline Inotropic support & no & no & no & no & no \\
\hline $\begin{array}{l}\text { Drainage from } \\
\text { NG tube }\end{array}$ & +++ & +++ & +++ & $\begin{array}{l}32 \mathrm{~h} \\
\text { hospitalization }\end{array}$ & 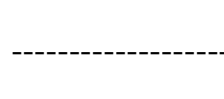 \\
\hline
\end{tabular}

Table 1: Laboratory and clinical parameters of the patients who were admitted to ICU. 


\begin{tabular}{|l|l|l|l|l|l|l|}
\hline & Fever $\left(\mathbf{C}^{\mathbf{0}}\right)$ & $\begin{array}{l}\text { Duration of } \\
\text { fever }\end{array}$ & $\begin{array}{l}\text { Pulse rate } \\
\mathbf{( b p m )}\end{array}$ & $\begin{array}{l}\text { Respiratory } \\
\text { rate (min) }\end{array}$ & $\begin{array}{l}\text { Blood } \\
\text { pressure(mmHg) }\end{array}$ & sO2 \\
\hline Case 1 & 39,3 & 19 hour & 123 & 30 & $169 / 84$ & 93 \\
\hline Case 2 & 39,9 & 22 hour & 116 & 25 & $84 / 50$ & 82 \\
\hline Case 3 & 38,8 & 4 hour & 152 & 18 & $114 / 76$ & 78 \\
\hline Case 4 & 38,3 & 1 hour & 155 & 22 & $74 / 35$ & 74 \\
\hline
\end{tabular}

Table 2: Vital parameters of the dying patients on the day of death.

\section{Discussion}

Initially mild disease may progress in a short time and lead to severe disease. Presence of central nervous system complications, deterioration of respiratory system findings, multi-organ dysfunction indicate a progressive disease and it is accepted as severe or complicated influenza [5, 6]. Acute respiratory distress syndrome (ARDS) may develop as the result of rapidly progressive lower respiratory tract infection, respiratory failure and persistent hypoxia (continuing hypoxia despite oxygen therapy). A study reports that need for ICU is seen in $25 \%$ of the patients who are hospitalized due to H1N1 infection [7] and the most common clinical condition includes severe ARDS without bacterial infection and accompanying multi-organ failure [8]. In another study, it was reported that mechanical ventilation (MV) was needed in approximately $65-85 \%$ of the patients who are followed up in ICU and they stay on MV for an average of 7-12 days, approximately one third of the patients who needed ICU had no previous health problems $[9,10]$. An underlying cause was detected in $70 \%$ of the patients who were hospitalized in another report from USA [11]. While there was not a difference between ICU patients with regard to gender, usually young adults (mean 40 years) needed ICU. Pregnant women who needed ICU were usually in the second-third trimester or within the first post-partum week $[8,12,13]$. Antiviral therapy for influenza is recommended to start within 48 hours after commencement of influenza-like symptoms in pregnant women who are in high risk group for influenza $[14,15]$.

In a study from our country, 7 out of 34 adult patients were reported to be followed up in ICU, 5 were applied MV and 5 were reported to die [16] and mean age of 9 patients who were in ICU was 41.3 years (23-59), while 3 patients did not have a coexisting disease, 6 had in another study [17]. There was not a difference between our patients with regard to gender and mean age was 41.3 (23-59). All dying patients were accepted as ARDS according to their chest $\mathrm{X}$-ray and arterial blood gas (ABG) values, there was one or two coexisting diseases. All of our patients were followed up on MV and only one could be extubated on day 3 and discharged on day 10.

Mortality varies between $15-54 \%$ in ICUs depending on the hospitals [1]. According to WHO report, mean duration of ICU stay is 5 days for patients with influenza, mean survival is 4 days after hospitalization (0-74). While antiviral treatment was started 48 hours after symptom onset in $61 \%$ of severely ill patients, it was started before 48 hours in $74 \%$ of mild cases [12]. High mortality rate in our study (80\%) arise from patients' admitting to hospital 4-5 days after symptom onset and starting treatment thereafter and coexisting diseases. 
In a study investigating chest X-ray images of the patients with $\mathrm{H} 1 \mathrm{~N} 1$, pathological findings were detected in the first radiography approximately half of the patients who needed ICU follow up??, all of the patients who needed ICU follow up [8]. Pathological radiological findings were detected in the first radiography in all of our patients who were followed up in ICU. A significant regression was detected on the radiographies on the day of death in dying patients 1 and 2 (Figure 1 and 2). Radiography was not obtained after admission in the third patient as she was pregnant and an improved radiological finding could not be obtained for the forth patient as he/she was lost within 36 hours. We suggested that the first two patients were lost due to another complication of influenza due to the absence of clinical improvement despite radiological improvement.

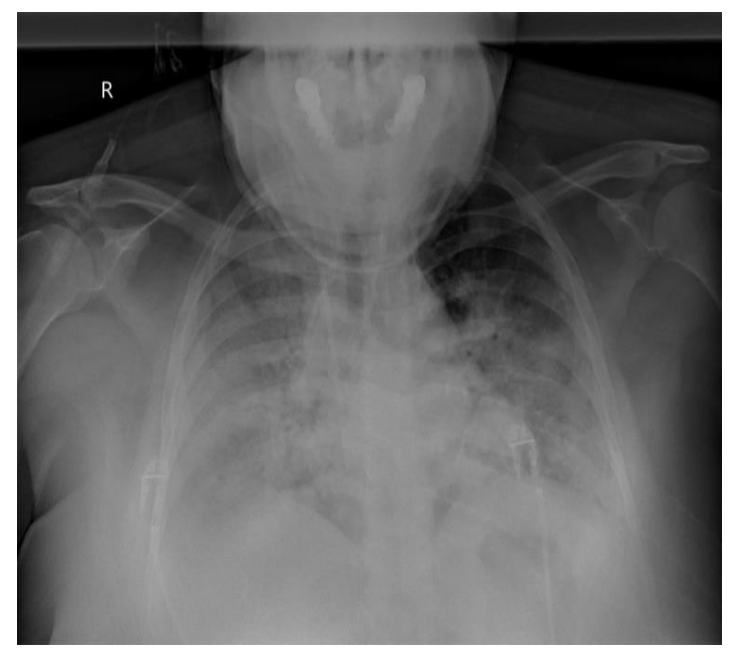

Figure 1a: Bilateral costo-phrenic sinuses are obliterated. Increased density and infiltration including air broncogram in all fields of the rigth lung, inferior and middle zones of the left lung.

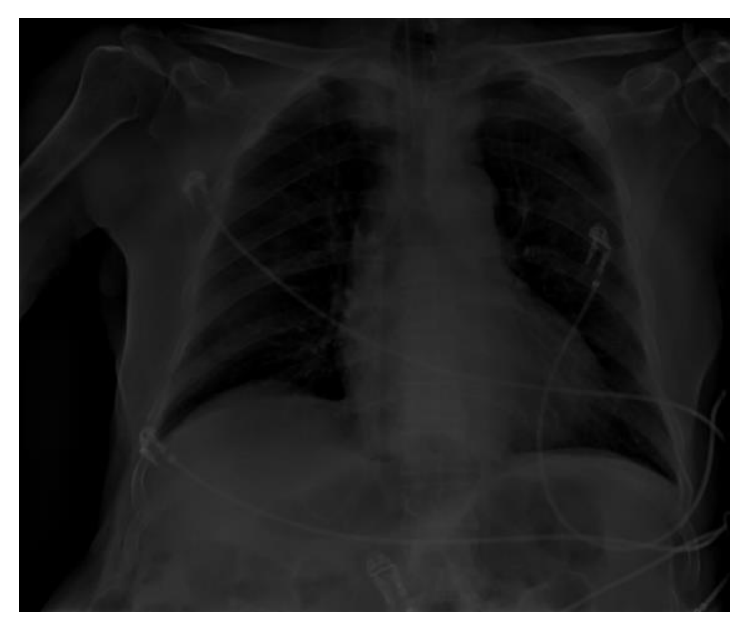

Figure 1b: Infiltrations including air broncograms, mainly in the superior zone of the right lung, less in bilateral middle and inferior zones. 


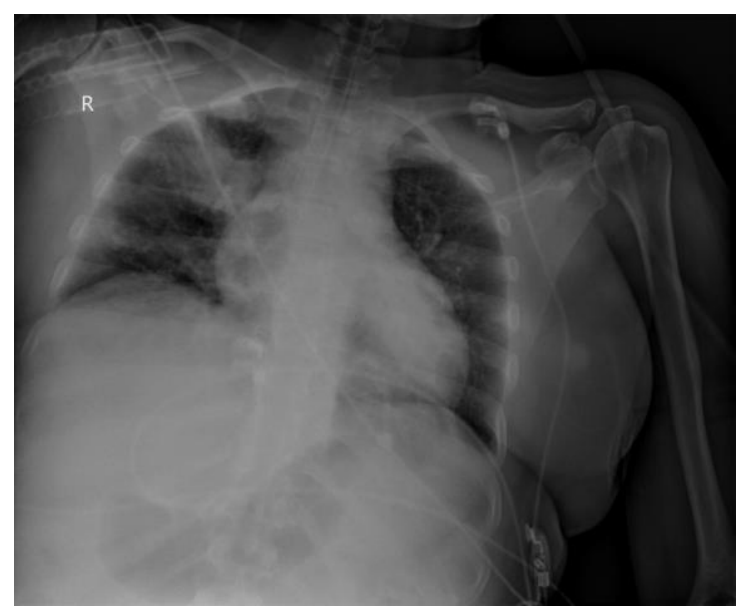

Figure 2a: Infiltrations including air broncograms, mainly in the superior zone of the right lung, less in bilateral middle and inferior zones.

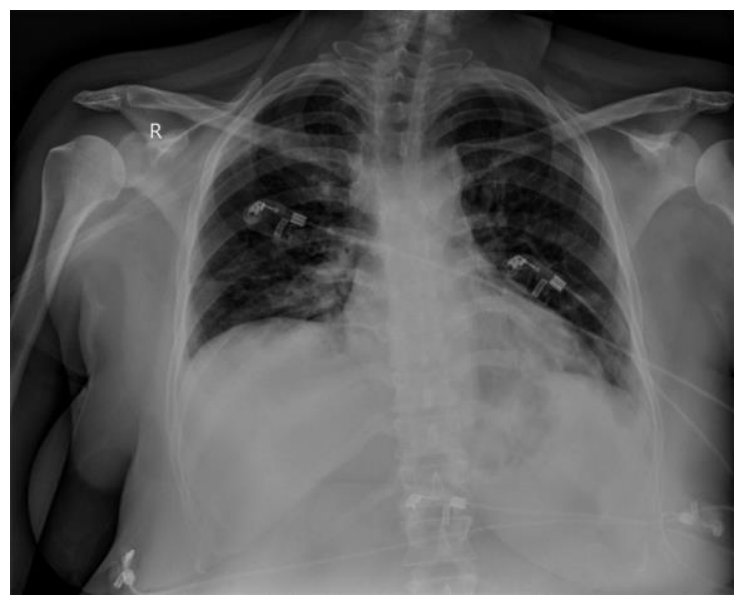

Figure 2b: The infiltration in the right superior zone is significantly improved, mild para-cardiac infiltration continues in the middle zone.

All of our patients were started $75 \mathrm{mg}$ oseltamivir bid. Oseltamivir is a pro-drug and known to be converted to its active metabolite, osletamivir carboxilate, with hepatic esterases and cerebral distribution of oseltamivir carboxilate is limited despite it passes blood-brain barrier [19]. So it is known to be ineffective in central nervous system involvement. Our patients' receiving sedation due to being on MV and having high respiratory rate and thereby hindering to evaluate CNS signs and symptoms, dying patients' not being hypotensive and even two patients' receiving intra-venous anti-hypertensive treatment although receiving sedation, two dying patients' not being able to tolerate intubation despite the significant radiological improvement suggest that these patients may have died from encephalitis-meningitis, not pneumonia. However clinical signs of CNS involvement (convulsion, fatigue) and level of coma could not be evaluated due to receiving sedation. Further investigations for CNS involvement could not be done as clinical stabilization could not be achieved even under MV support. 
In conclusion, we suggest that presence of a co-existing disease and starting treatment late are the main factors which affect mortality in patients with H1N1. In addition, CNS involvement should be considered in patients whose radiological parameters improve however whose clinical condition is still poor and required examinations should be

done. Mortality rate may be reduced by this way. We also consider that studies are required to evaluate drug absorption level through monitoring naso-gastric tube drainage.

\section{References}

1. Sullivan SJ, Jacobson RM, Dowdle WR, et al. H1N1 influenza. Mayo Clin Proc 85 (2009): 64-76.

2. Dawood FS, Jain S, Finelli L, et al. Emergence of a novel swine-origin influenza A (H1N1) virus in humans. N Engl J Med 360 (2009): 2605-2615.

3. World Health Organization (WHO). WHO guidelines for pharmacological management of pandemic (H1N1) 2009 influenza and other influenza viruses. Geneva, Switz: World Health Organization (2009).

4. Centers for Disease Control and Prevention (CDC). H1N1 flu. Updated interim recommendations for the use of antiviral medications in the treatment and prevention of influenza for the 2009-2010 season. Atlanta, GA: Centers for Disease Control and Prevention (2009).

5. World Health Organization (WHO). WHO guidelines for pharmacological management of pandemic (H1N1) 2009 influenza and other influenza viruses. Geneva, Switz: World Health Organization (2009).

6. Centers for Disease Control and Prevention (CDC). H1N1 flu. Updated interim recommendations for the use of antiviral medications in the treatment and prevention of influenza for the 2009-2010 season. Atlanta, GA: Centers for Disease Control and Prevention (2009).

7. Jain S, Kamimoto L, Bramley A, , et al. Hospitalized patients with 2009 H1N1 influenza in the United States, April-June 2009. N Engl J Med 361 (2009): 1935-1944.

8. Miller RR, Markewitz BA, Rolfs RT, et al. Clinical findings and demographic factors associated with intensive care unit admission in Utah due to 2009 novel influenza A (H1N1) infection. Chest 2009 0: chest.09-2517v1-chest. 09-2517.

9. Webb SA, Pettilä V, Seppelt I, et al. ANZIC Influenza Investigators. N Engl J Med. 361 (2009): 19251934.

10. Kumar A, Zarychanski R, Pinto R, et al. Critically ill patients with 2009 influenza A (H1N1) in Canada. JAMA 302 (2009): 1872-1879.

11. Louie JK, Acosta M, Winter K, et al. Factors associated with death or hospitalization due to pandemic 2009 influenza A (H1N1) infection in California. JAMA 302 (2009):1896.

12. WHO:Clinical management of human infection with pandemic (H1N1) (2009).

13. Cullen G, Martin J, O'Donnell J, et al. Surveillance of the first 205 confirmed hospitalised cases of pandemic H1N1 influenza in Ireland, 28 April-3 October 2009. Euro Surveill 14 (2009): 19389.

14. Hewagama S, Walker SP, Stuart RL, et al. H1N1 Infl uenza A and Pregnancy Outcomes in Victoria, Australia. Clin Infect Dis 50 (2010): 686-690.

15. Fridman D, Kuzbari O, Minkoff H. Novel influenza H1N1 in pregnancy: a report of two cases. Infect Dis Obstet Gynecol. (2009): 514353.

16. Saltoğlu N, Balkan İI. H1N1: Klinik görünümler ANKEM Derg 24 (2010): 196-200. 
17. CAN Ö. Pandemik influenza A (H1N1) 2009 virüsü ve klinik tecrübemiz.Yoğun Bakım Dergisi 1 (2010): $1-12$.

18. Quispe-Laime AM, Bracco JD, Barberio PA, et al. H1N1 influenza A virus-associated acute lung injury: response to combination oseltamivir and prolonged corticosteroid treatment. Intensive Care Med 36 (2010): $33-41$.

19. Lindemann L, Jacobsen $\mathrm{H}$, Schuhbauer D, et al. In vitro pharmacological selectivity profile of oseltamivir prodrug (Tamiflu) and active metabolite. Eur J Pharmacol 628 (2010): 6-10.

(C)
BY 